University of Nebraska - Lincoln

DigitalCommons@University of Nebraska - Lincoln

Sociology Department, Faculty Publications

Sociology, Department of

2015

Patterns of substance use initiation among Indigenous adolescents

Les B. Whitbeck

University of Nebraska-Lincoln, Iwhitbeck2@unl.edu

Brian E. Armenta

University of Nebraska-Lincoln, berikarmenta@gmail.com

Follow this and additional works at: https://digitalcommons.unl.edu/sociologyfacpub

Part of the Family, Life Course, and Society Commons, and the Social Psychology and Interaction

Commons

Whitbeck, Les B. and Armenta, Brian E., "Patterns of substance use initiation among Indigenous adolescents" (2015). Sociology Department, Faculty Publications. 547.

https://digitalcommons.unl.edu/sociologyfacpub/547

This Article is brought to you for free and open access by the Sociology, Department of at DigitalCommons@University of Nebraska - Lincoln. It has been accepted for inclusion in Sociology Department, Faculty Publications by an authorized administrator of DigitalCommons@University of Nebraska - Lincoln. 
Published in final edited form as:

Addict Behav. 2015 June ; 45: 172-179. doi:10.1016/j.addbeh.2015.01.006.

(c) 2015 Elsevier. Used by permission.

\title{
Patterns of substance use initiation among Indigenous adolescents ${ }^{\star}$
}

\author{
Les B. Whitbeck ${ }^{\star}$ and Brian E. Armenta \\ Department of Sociology, University of Nebraska-Lincoln, United States
}

\begin{abstract}
Background-The data for this study come from an eight-wave panel study of Indigenous (Canadian First Nations and American Indian) adolescents from three U.S. reservations and four Canadian reserves.
\end{abstract}

Objectives-Our objective was to investigate variations in patterns of substance use initiation from early adolescence through early adulthood using data collected annually for 8 years.

Method-At baseline the sample included 675 Indigenous adolescents $(M$ age $=11.10, S D=.83$; $50.3 \%$ girls). First, we calculated cumulative rates of substance use initiation by age. We then examined whether the cumulative initiation rates were moderated by gender using logistic regression analyses. Second, we calculated hazard rates for substance use initiation by age. Third, we focused on the ordering of two substances, paired two substances, and three substance initiation sequences.

Results-If one looks only at the cumulative rates of substance use initiation there appears to be support for a sequential progression of substance use during early adolescence. In contrast to the cumulative rates of substance use initiation, the hazard analyses showed a much more mixed, less progressive sequence. Among two substance pairings a nicotine to marijuana initiation sequence was most likely, followed by a nicotine to alcohol sequence. An alcohol to marijuana sequence was nearly twice as likely as a marijuana to alcohol sequence. Refined analyses to conform to those of many of the traditional gateway studies by introducing paired two substance orderings indicated that nicotine and/or alcohol prior to marijuana use was by far the most likely sequence. In two of the three most likely three substance sequences (nicotine to alcohol to marijuana and nicotine to marijuana to alcohol) nicotine was the first substance initiated.

Conclusion-This study refines the gateway hypothesis for Indigenous adolescents by providing an in-depth analysis of substance use initiation. The only evidence for a "gateway" substance that

\footnotetext{
This research was funded by the National Institute on Drug Abuse (DA13580) and the National Institute of Mental Health (MH67281), and the National Institute of Alcohol Abuse and Alcoholism (AA020299), Les B. Whitbeck, Principal Investigator.

*Corresponding author at: Department of Sociology, 739 Oldfather Hall, University of Nebraska Lincoln, 68588, United States. Tel.: +1 402472 562. 1whitbeck2@unl.edu (L.B. Whitbeck).

Contributors

Dr. Whitbeck is the principal investigator on the study and contributed to a substantial portion of the writing and interpretation of results for this paper. Dr. Armenta conducted statistical analyses and contributed to a substantial portion of the writing and interpretation of the results for this paper. All authors have reviewed and approved the final manuscript.

Conflict of interest

All authors declare that they have no conflict of interest.
} 
emerged in our analyses was for nicotine use which was likely to precede alcohol and marijuana use in both two-substance pairings and to a lesser extent in three-substance initiation sequences.

\section{Keywords}

Indigenous adolescents; Substance use; Gateway substances

\section{Introduction}

The concept of systematic developmental stages in the progression of substance use initiation (the gateway hypothesis) is now nearly four decades old (Hamburg, Kraemer, \& Jahnke, 1975; Kandel, 1975). The hypothesized gateway sequence is from milder, commonly used, legal substances such as tobacco and alcohol (usually considered together), to more illicit drugs such as marijuana, hallucinogens and hard drugs (Kandel \& Yamaguchi, 2002; Kandel, Yamaguchi, \& Chen, 1992). The gateway hypothesis has been investigated across multiple ethnic and racial groups (Novins \& Barón, 2004; Wu, Temple, Shokar, Nguyen-Oghalai, \& Grady, 2010), cross-nationally (Degenhardt et al., 2008; Kandel \& Yamaguchi, 1999; Luengo et al., 2008; Wells \& McGee, 2008), and with animal studies (Ellgren, Spano, \& Hurd, 2007; Higuera-Matas et al., 2008; Pistis et al., 2004). The evidence for specific patterns of progression has been inconsistent across social class, ethnicity, gender, race, and for serious drug users (Mackesy-Amiti, Fendrich, \& Goldstein, 1997; Vaughn, Wallace, Perron, Copeland, \& Howard, 2008).

Recent studies of patterns of substance use initiation among American Indian adolescents (Novins \& Barón, 2004; Novins, Beals, \& Mitchell, 2001; Whitesell et al., 2012) have shown at best only mixed support for the gateway hypothesis. Building on this previous research, we revisited the hypothesis with an in-depth investigation of the actual distributions of substance use initiation and the variation in these sequences by gender. We investigated 1) cumulative rates of substance use initiation by age; 2) hazard rates for substance use initiation by age; 3) two substance orderings of initiation; 4) paired two substance orderings which encompass the traditional gateway hypothesis (e.g., legal substances such as nicotine/alcohol $\rightarrow$ illicit substances such as marijuana) (Kandel $\&$ Yamaguchi, 2002; Kandel et al., 1992); and 4) three substance orderings. This approach captures the substantial variation of substance initiation use patterns within a sample of Indigenous (American Indians and Canadian First Nations) adolescents as they progressed from age 8 to 16 years.

\section{Patterns of Indigenous adolescent substance use initiation}

Although epidemiologic evidence indicates substantial differences in drug and alcohol use across and within AIAN cultures (see Beals et al., 2005; May, 1994; Whitbeck, Hoyt, Johnson, \& Chen, 2006), there is consensus that Indigenous adolescents tend to experiment with substances very early and progress to regular use more rapidly than do non-Indigenous adolescents (Bachman et al., 1991; Beauvais, 1998; Blum, Harmon, Harris, Bergeisen, \& Resnick, 1992). We now have decades of evidence that Indigenous young people are likely engage in early onset tobacco use (Forster, Brokenleg, Rhodes, Lamont, \& Poupart, 2008; 
Substance Abuse and Mental Health Services Administration (SAMSHA), 2003; Whitbeck, Yu, McChargue, \& Crawford, 2009), alcohol use (Cheadle \& Whitbeck, 2011; May, 1994; Miller, Beauvais, Burnside, \& Jumper-Thurman, 2008), marijuana use (Cheadle \& Sittner Hartshorn, 2012; Novins \& Mitchell, 1998; Whitesell et al., 2007), and other drug use (SAMSHA, 2010). Such early use fosters movement from easily accessible legal substances (e.g., tobacco, alcohol) to those less available and often illegal (e.g., marijuana, hallucinogens, hard drugs).

Studies on patterns of substance abuse initiation among Indigenous adolescents have shown little support for the traditional gateway hypothesis. Using retrospective data, Novins et al. (2001) found that among 1562 American Indian high school students from four rural communities in the West, those who had used three or more substances had a pattern of substance use that was inconsistent with gateway theories of initiation. In a subsequent longitudinal study, Novins and Barón (2004) reported that progression patterns varied by American Indian community and by season of the year. In general, the adolescents who initiated substance use with marijuana and inhalants were more likely to progress to other illicit drugs than were those whose first substance use was alcohol only. More recently, Whitesell et al. (2012) reported that the risk for tobacco and marijuana use preceded the risk for alcohol use among 450 Northern Plains adolescents who were surveyed over four years.

The research reported here extends this previous work on substance use initiation patterns in several ways. First, it investigates sequential patterns of substance use onset in an Indigenous culture outside the Northern Plains. Second, we employed multiple analytic approaches to evaluate variations in potential sequences that may be methodological artifacts (i.e. cumulative rates of use vs. hazard analyses). Third, we investigated two sequences, paired two sequence, and three-sequence initiation patterns. Finally, we compared the sequence patterns for adolescent males and females. The result is the most comprehensive presentation to date of various patterns of substance use initiation among Indigenous adolescents.

\section{Method}

\subsection{Study design and participants}

The study from which the data were drawn was designed in partnership with three U.S. reservations and four Canadian First Nations reserves. The reservations/reserves share a common cultural tradition and language with minor regional variations in dialects. As part of confidentiality agreements the names of the cultural group and participating reservations/ reserves are not provided. At each site advisory boards appointed by tribal councils were responsible for advising the research team on questionnaire development and supervising study personnel. At each wave, participants completed in-person interviews at their homes. All interviews were completed in English. The interviewers, as well as the onsite coordinators, all were approved by tribal advisory boards and were either enrolled tribal members or, in a very few cases, non-member spouses of enrollees. Interviewers were trained before each wave concerning methodological guidelines of personal interviewing and protection of human subjects. 
Prior to the first wave of data collection each participating reservation/reserve provided us with a list of all families with tribally-enrolled children aged 10-12 years who lived on or proximate (within 50 miles) to the reservation/reserve. An attempt to contact all families was made in order to achieve a representative sample of the communities. Families were formally recruited for the study through personal interviewer visits, during which the families were presented with a culturally traditional gift and an overview of the project. For those families who agreed to participate (79.4\%), both the target adolescent and at least one adult caretaker were interviewed once per year over an eight-year period, beginning in 2002. For each wave of the study participating families were given $\$ 40$ for each participant (i.e., adolescent and caregiver or caregivers) as compensation. The study was approved onsite by tribally appointed advisory boards and conducted in compliance with the institutional review board at the University of Nebraska-Lincoln.

At Wave 1 the sample included 675 adolescents ( $M$ age $=11.10, S D=.83 ; 50.3 \%$ girls $)$, of which $94.7 \%$ completed Wave 2 (50.1\% girls), 92.9\% completed Wave 3 (49.8\% girls), $87.3 \%$ completed Wave 4 (50.8\% girls), 89.8\% completed Wave 5 (50.8\% girls), $87.7 \%$ completed Wave 6 (50.3\% girls), 84.4\% completed Wave 7 (51.1\% girls), and $77.6 \%$ completed Wave 8 (52.9\% girls).

\subsection{Age of substance use initiation measures}

At each wave, participants were first asked whether or not they had ever (1) smoked a cigarette, (2) drank beer, wine, or other alcoholic beverages, and (3) smoked marijuana. Participants who indicated that they had tried a given substance were then asked to indicate the age at which they had first tried that substance. We created an age of initiation variable for each of the substances separately. Values were based on the age of first use reported during the wave that participants first reported having used a given substance. We used all available data; thus, if a participant dropped out of the study at Wave 5, we included his or her data from Waves 1-4 in our calculations. The number of participants who initiated each of the substances at each age is reported in Table 1.

\section{Analytic strategy}

We conducted three sets of analyses. First, we calculated cumulative rates of substance use initiation by age. These values represent the number of participants who reported having used a given substance at or prior to a given age. We then examined whether the cumulative initiation rates were moderated by gender using logistic regression analyses. Second, we calculated hazard rates for substance use initiation by age. These values represent the risk for substance use initiation at each age, and are calculated by dividing the number of participants who initiated a given substance at a given age by the number of participants who had not initiated that substance at an earlier age. We then examined whether the hazard rates were moderated by gender using logistic regression analyses. The rates of initiation prior to age 8 were sporadic. Moreover, with very few exceptions, the youngest participants at the final wave of the study were 16 . We thus focused our analyses on initiation and hazard rates from ages 8 to 16 years. 
The final set of analyses focused on the ordering of substance use initiation. We considered all possible combinations of substance use initiation, including (a) two substance orderings (e.g., nicotine $\rightarrow$ alcohol), (b) paired two substance orderings (e.g., nicotine and/or alcohol $\rightarrow$ marijuana, nicotine $\rightarrow$ alcohol and/or marijuana), and (c) three substance orderings (e.g., nicotine $\rightarrow$ alcohol $\rightarrow$ marijuana).

\subsection{Two substance orderings}

We computed an age of initiation ordering variable for all possible two substance orderings (i.e., nicotine $\rightarrow$ alcohol; nicotine $\rightarrow$ marijuana; alcohol $\rightarrow$ marijuana; alcohol $\rightarrow$ nicotine; marijuana $\rightarrow$ nicotine; and marijuana $\rightarrow$ alcohol), resulting in six possible categories for each pairing. For illustration, consider the nicotine $\rightarrow$ alcohol use initiation ordering. Participants were categorized as (1) never used nicotine or alcohol, (2) used nicotine and alcohol with initiation at the same age, (3) used nicotine only, (4) used nicotine at an earlier age than alcohol, (5) used alcohol only, and (6) used alcohol at an earlier age than nicotine. We then summarized these patterns as (a) non-informative regarding the given ordering (i.e., patterns 1 and 2), (b) consistent with the given ordering (i.e., patterns 3 and 4), and (c) inconsistent with the given ordering suggested (i.e., patterns 5 and 6). This was done for each of the two substance orderings.

Using the summarized data, for each two substance use orderings separately, we compared the proportion of participants in the consistent category to the proportion of participants in the inconsistent and non-informative categories. To this end, we computed three dummy variables, including (a) consistent vs. inconsistent/non-informative, (b) inconsistent vs. consistent/non-informative, and (c) non-informative vs. consistent/inconsistent. We then tested the null hypothesis that the proportions of participants in the inconsistent and noninformative categories were statistically equivalent to the proportion of participants in the consistent category. To do this, we first obtained the observed distribution for the consistent dummy variable (i.e., percentage in the consistent category vs. percentage not in the consistent category). We then used chi-square analyses to test whether the expected distributions for the remaining two dummy variables (i.e., inconsistent and non-informative) were statistically equivalent or different from the observed distribution of the consistent dummy variable. A statistically significant chi-square value would indicate that participants are not equally likely, for example, to be in the consistent and inconsistent categories, with the direction of the difference dictated by the observed frequencies of participants in the categories. Using the same general approach, we compared the proportions of participants in the consistent category across the six potential substance initiation orderings. For example, the proportion of participants in the consistent category for the nicotine $\rightarrow$ alcohol ordering was compared to the remaining substance use initiation orderings (e.g., nicotine $\rightarrow$ marijuana, alcohol $\rightarrow$ nicotine). Finally, we considered potential gender differences by conducting these analyses separately for boys and girls.

\subsection{Paired two substance orderings}

We computed age of initiation ordering variables for all possible paired two substance combinations (i.e., nicotine and/or alcohol $\rightarrow$ marijuana; nicotine and/or marijuana $\rightarrow$ alcohol; alcohol and/or marijuana $\rightarrow$ nicotine; nicotine $\rightarrow$ alcohol and/or marijuana; 
alcohol $\rightarrow$ nicotine and/or marijuana; and marijuana $\rightarrow$ nicotine and/or alcohol). We then computed age of initiation ordering variables and followed the same analytic strategy as described for the two substance orderings. Notably, the nicotine and/or alcohol $\rightarrow$ marijuana ordering is a direct test of the original gateway hypothesis (i.e., licit/mild substances $\rightarrow$ illicit/heavier substances).

\subsection{Three substance orderings}

We computed age of initiation ordering variables for all possible three substance orderings (i.e., nicotine $\rightarrow$ alcohol $\rightarrow$ marijuana; nicotine $\rightarrow$ marijuana $\rightarrow$ alcohol; alcohol $\rightarrow$ nicotine $\rightarrow$ marijuana; alcohol $\rightarrow$ marijuana $\rightarrow$ nicotine; marijuana $\rightarrow$ nicotine $\rightarrow$ alcohol; and marijuana $\rightarrow$ alcohol $\rightarrow$ nicotine). There were 25 possible patterns for each ordering, which are shown in Appendix A. As with the previous two analyses we summarized the patterns into consistent, inconsistent, and non-informative categories (categorization scheme shown in Appendix A). We again followed the same analytic strategy outlined above.

\section{Results}

\subsection{Cumulative rates of substance use initiation}

The cumulative rates (expressed in percentages) for the entire sample by age and substance are reported in Table 2 (total column) and are represented pictorially in Fig. 1. As can be seen in the figure, there was a steady increase in nicotine initiation from ages 8 (or younger) to 16 ; there was a steady increase in alcohol initiation from ages 8 (or younger) to 16 , with the sharpest increase occurring between ages 11 and 14; and there was a steady increase in marijuana initiation from ages 8 (or younger) to 16, with the sharpest increase occurring between ages 10 and 14 . Considering the cumulative initiation rates in combination, across all ages, more participants had initiated nicotine and alcohol than marijuana. In addition, more participants had initiated nicotine than alcohol from ages 8 (or younger) to 13. At age 14 , however, the number of participants who had initiated nicotine and alcohol was roughly equivalent, and more participants had initiated alcohol than nicotine at ages 15 and 16.

5.1.1. Gender comparisons-The results of the logistic regression analyses testing for gender differences in cumulative initiation rates by age also are reported in Table 2 (expressed as odds ratios). Boys were more likely than were girls to have initiated nicotine use at or before age 8 ; there were no gender differences in cumulative nicotine initiation rates between ages 9 and 11; and girls were more likely than were boys to have initiated nicotine use from ages 12 to 16 . In addition, boys were more likely to have initiated alcohol use than were girls at or before age 8 and from ages 9 to 11 but there were no gender differences in alcohol initiation from ages 12 to 16. Finally, boys were more likely to have initiated marijuana use than were girls at or before age 8 and from ages 9 to 10; there were no gender differences in marijuana initiation from ages 11 to 14 ; and girls were more likely than were boys to have initiated marijuana use from ages 15 to 16 . 


\subsection{Hazard rates for substance use initiation}

The hazard rates (expressed in percentages) for the entire sample by age and substance are reported in Table 2 (total column) and are represented pictorially in Fig. 1. The risk (or hazard) for nicotine increased from ages 8 (or younger) to 11, essentially plateaued from 11 to 14 and decreased thereafter. The risk for alcohol initiation increased steadily from ages 8 (or younger) to 15 and decreased thereafter. The risk for marijuana initiation was quite low from ages 8 (or younger) to 10 , increased from ages 11 to 14 , then decreased from ages 15 to 16 .

5.2.1. Gender comparisons-The hazard rates for boys and girls are reported in Table 2, as are the results of the logistic regression analyses testing for gender differences. The adolescent boys were at greater risk for nicotine initiation than were girls at or before age 8; girls were at greater risk for nicotine initiation than were boys at ages 10 and 12; and risk for nicotine initiation was similar for boys and girls at the remaining ages. In addition, boys were at a higher risk for alcohol initiation than were girls at ages 8 (or younger) and 10, while risk for alcohol initiation was similar for boys and girls at the remaining ages. Finally, boys were at greater risk for marijuana initiation at ages 8 (or younger) and 9; there were no gender differences from ages 10 to 14 and at age 16; and girls were at greater risk for marijuana initiation than were boys at age 15 .

\subsection{Two substance orderings}

The results for the two substance orderings analyses are shown in Table 3.

5.3.1. Consistency vs. inconsistency within ordering patterns-For sample as a whole, there was greater consistency than inconsistency for the gateway hypothesis for the nicotine $\rightarrow$ alcohol, nicotine $\rightarrow$ marijuana, and alcohol $\rightarrow$ marijuana orderings. By contrast, there was greater inconsistency than consistency for the alcohol $\rightarrow$ nicotine, marijuana $\rightarrow$ nicotine, and marijuana $\rightarrow$ alcohol orderings. The pattern of results for the sample as a whole was similar for boys and girls separately.

5.3.2. Consistency across ordering patterns-For the sample as a whole, the greatest consistency was for the nicotine $\rightarrow$ marijuana ordering, and the consistency of this ordering was significantly greater than the remaining orderings. The next highest level of consistency was for the nicotine $\rightarrow$ alcohol and alcohol $\rightarrow$ marijuana orderings, which were statistically equivalent to each other, and significantly greater than the remaining orderings. This was followed by the alcohol $\rightarrow$ nicotine and marijuana $\rightarrow$ alcohol orderings, which were statistically equivalent to each other, and which were significantly greater than the marijuana $\rightarrow$ nicotine ordering.

These orderings differed slightly for boys and girls. For boys, the greatest consistency was for the nicotine $\rightarrow$ marijuana ordering, followed, respectively, by the alcohol $\rightarrow$ marijuana, nicotine $\rightarrow$ alcohol, alcohol $\rightarrow$ nicotine, marijuana $\rightarrow$ alcohol, and marijuana $\rightarrow$ nicotine orderings. For girls, the greatest consistency was for the nicotine $\rightarrow$ marijuana ordering, followed, respectively, by the nicotine $\rightarrow$ alcohol, alcohol $\rightarrow$ marijuana, marijuana $\rightarrow$ alcohol, alcohol $\rightarrow$ nicotine, and marijuana $\rightarrow$ nicotine orderings. 


\subsection{Paired two substance orderings}

The results for the paired two substance orderings analyses are shown in Table 4.

5.4.1. Consistency vs. inconsistency within ordering patterns-For sample as a whole, there was greater consistency than inconsistency for the nicotine and/or alcohol $\rightarrow$ marijuana, nicotine and/or marijuana $\rightarrow$ alcohol, and nicotine $\rightarrow$ alcohol and/or marijuana orderings. By contrast, there was greater inconsistency than consistency for the alcohol and/or marijuana $\rightarrow$ nicotine, alcohol $\rightarrow$ nicotine and/or marijuana, and marijuana $\rightarrow$ nicotine and/or alcohol orderings. The pattern of results for the sample as a whole was similar for boys and girls separately.

\subsubsection{Consistency in orderings across ordering patterns-For the sample as a} whole, the greatest consistency was for the nicotine and/or alcohol $\rightarrow$ marijuana ordering, and the consistency of this ordering was significantly greater than the remaining orderings. Notably, this pattern reflects the traditional gateway hypothesis (i.e., licit $\rightarrow$ illicit substance initiation). The next highest level of consistency was for the nicotine and/or marijuana $\rightarrow$ alcohol ordering, followed, respectively, by the nicotine $\rightarrow$ alcohol and/or marijuana, alcohol and/or marijuana $\rightarrow$ nicotine, alcohol $\rightarrow$ nicotine and/or marijuana, and marijuana $\rightarrow$ nicotine and/or alcohol orderings. The consistency for each of the orderings was significantly different from the consistency of all other orderings. The consistency pattern for girls followed the same order as the full sample. The same was true for boys, with one exception; specifically, the consistency was greater for the alcohol and/or marijuana $\rightarrow$ nicotine ordering than it was for the nicotine $\rightarrow$ alcohol and/or marijuana ordering.

\subsection{Three substance orderings}

The results for the three substance orderings analyses are shown in Table 5.

\subsubsection{Consistency vs. inconsistency within ordering patterns-Across all} orderings, there was significantly greater inconsistency than consistency. This was true for the sample as a whole and for boys and girls separately. It also should be noted that there was far fewer participants who fell into the consistent category for each of the substance use orderings (maximum consistency $=18.9 \%$ ) compared to the two substance orderings (maximum consistency $=61.9 \%$ ) and paired two substance orderings (maximum consistency $=69.5 \%)$.

\subsubsection{Consistency in orderings across ordering patterns-For the sample as a} whole, the greatest consistency was for the nicotine $\rightarrow$ alcohol $\rightarrow$ marijuana, alcohol $\rightarrow$ nicotine $\rightarrow$ marijuana, and nicotine $\rightarrow$ marijuana $\rightarrow$ alcohol orderings, each of which were statistically equivalent to each other and significant greater than the remaining patterns. The next highest level of consistency was for the alcohol $\rightarrow$ marijuana $\rightarrow$ nicotine ordering, which was significantly greater than the remaining orderings. The lowest level of consistency was for the marijuana $\rightarrow$ nicotine $\rightarrow$ alcohol and marijuana $\rightarrow$ alcohol $\rightarrow$ nicotine orderings, which were statistically equivalent to each other. 
The gender differences in the consistency of ordering patterns were more pronounced for the three substance orderings than they were for the two substance and paired two substance orderings. For boys, the greatest consistency was for the alcohol $\rightarrow$ nicotine $\rightarrow$ marijuana ordering, which was statistically greater than the remaining orderings. The next highest level of consistency was for the nicotine $\rightarrow$ alcohol $\rightarrow$ marijuana, nicotine $\rightarrow$ marijuana $\rightarrow$ alcohol, and alcohol $\rightarrow$ marijuana $\rightarrow$ nicotine orderings, each of which was statistically equivalent to each other and statistically greater than the remaining orderings. As with the full sample, the lowest level of consistency was for the marijuana $\rightarrow$ nicotine $\rightarrow$ alcohol and marijuana $\rightarrow$ alcohol $\rightarrow$ nicotine orderings, which were statistically equivalent to each other. For girls, the greatest consistency was for the nicotine $\rightarrow$ alcohol $\rightarrow$ marijuana ordering, which was statistically greater than the remaining orderings. The next highest level of consistency was for the nicotine $\rightarrow$ marijuana $\rightarrow$ alcohol and alcohol $\rightarrow$ nicotine $\rightarrow$ marijuana orderings, which were statistically equivalent to each other and statistically greater than the remaining patterns. These orderings were followed by the alcohol $\rightarrow$ marijuana $\rightarrow$ nicotine ordering, which was statistically greater than the marijuana $\rightarrow$ nicotine $\rightarrow$ alcohol and marijuana $\rightarrow$ alcohol $\rightarrow$ nicotine orderings, which were statistically equivalent to each other.

\section{Discussion and conclusions}

If one looks only at the cumulative rates of substance use initiation there appears to be support for a sequential progression of substances use during early adolescence. Nicotine use emerged earlier than other substance use through age 12, after which initiation of alcohol use catches up and then surpasses new initiations nicotine use. The cumulative rates of initiation of marijuana use remained lower than that of the other two substances though the slope of increase is similar. Hazard analyses present a slightly different picture. First, the hazard curves are much closer to one another in age range. Nicotine use emerges slightly earlier than the other two substances through age 12, after which it plateaus then declines. Risk for initiation of alcohol use surpasses that of other substances after age 12 years and, although the rate of alcohol initiation declines after age 14, the decrease is not as dramatic as that for nicotine and marijuana. The risk of marijuana initiation is nearly instep with that of alcohol use through age 12, almost converges with alcohol use at age 13 and then declines consonant with nicotine initiation. In contrast to the cumulative rates of substance use initiation, the hazard analyses show a more mixed, less progressive sequence. In particular, there is little difference in rates of early initiation of alcohol and marijuana prior to age 12 .

Among two substance pairings a nicotine to marijuana initiation sequence was most likely, followed by a nicotine to alcohol sequence. An alcohol to marijuana sequence was nearly twice as likely as a marijuana to alcohol sequence. Smoking marijuana prior to smoking tobacco was the least likely among the two substance pairing. In general, the two substance pairings indicate that nicotine is the preeminent gateway substance for both marijuana and alcohol.

We then refined the analyses to conform to those of many of the traditional gateway studies by introducing paired two substance orderings. Nicotine and/or alcohol prior to marijuana use was by far the most likely sequence, followed by a sequence of nicotine and/or 
marijuana preceding alcohol use. As in the two substance pairings, nicotine in combination with either alcohol or marijuana was the common gateway substance.

This pattern held for the three substance initiation comparisons. In two of the three most likely three substance sequences (nicotine to alcohol to marijuana and nicotine to marijuana to alcohol) nicotine was the first substance initiated. However, an alcohol to nicotine to marijuana sequence was just as likely as the nicotine, alcohol, marijuana sequence. A three substance sequence beginning with marijuana use was least likely.

Although there were some variations in initiation sequences by gender, nicotine was the predominant gateway substance for both boys and girls in two substance pairings and paired two substances. The primary deviation from the primacy of nicotine was among boys where alcohol was likely to precede nicotine use in $18.9 \%$ of three substance sequences compared to $13.2 \%$ of nicotine, alcohol, and marijuana sequences and $12.6 \%$ of nicotine, marijuana, and alcohol sequences. Although surpassed by alcohol initiation in three substance sequences among boys, the overall impact of nicotine initiation is still apparent. When we break out all of the potential sequences it becomes evident that the primary "gateway" substance is nicotine.

\subsection{Limitations}

Because this research was limited to a single culture, the results may not be generalizable to other Indigenous cultures and perhaps not even to urban Indigenous people in this same culture. Also, our approach was community based participatory research which means that almost all of the interviewers were enrolled tribal members from the participating communities. Although the families were given the opportunity to decline particular interviewers if they were related to them or if they were otherwise uncomfortable with the interviewer, local interviewers may have resulted in under reporting that may have introduced a conservative bias. Another potential limitation is our use of retrospective reports (e.g. Wave 1 reports of "ever used"). We should note, however, that these are not adult reports of behaviors during adolescence, but adolescent reports from a year or two ago. Perhaps the most significant limitation of these analyses is that they do not extend to the initiation of hard drugs. At this point, the cell sizes for hard drug use were so small, that they could not be included in the analyses.

\section{Conclusions}

The initiation patterns we identified suggest that the primary evidence for a "gateway" substance is nicotine use. Nicotine was likely to precede alcohol and marijuana use in twosubstance, and paired two substance sequences and to a lesser extent in three-substance initiation sequences. Nicotine as a "gateway" substance is not a trivial concern. It is not only a significant health risk (Centers for Disease Control and Prevention, 2003; Willi, Bodenmann, Ghali, Faris, \& Cornuz, 2007), it also is associated with a cluster of other adolescent problems such as disruptive behaviors (Breslau, 1995; Lawrence, Mitrou, Sawyer, \& Zubrick, 2010; Whitbeck, Sittner Hartshorn, McQuillan, \& Crawford, 2012), depressive symptoms (Breslau, Peterson, Schultz, Chilcoat, \& Andreski, 1998; Fergusson, 
Lynskey, \& Horwood, 1996; Whitbeck et al., 2009), and, as these results suggest, other substance use.

Nicotine use emerges early, it is highly addictive (Anthony, Warner, \& Kessler, 1994), and once one is nicotine dependent it is very difficult to quit (Juliano, Donny, Houtsmuller, \& Stitzer, 2006). Because of its addictive properties there should be early and repeated universal preventions for Indigenous pre-adolescents. Such early prevention efforts may not only curtail nicotine dependence, but may deter subsequent substance use initiation as well. Because nicotine use begins early and progresses quickly into addiction it has been call a "pediatric disease" (Upadhyaya, Deas, Brady, \& Kruesi, 2002) with lifelong health consequences. One of these consequences may be its role as a "gateway" to other substances.

\section{Acknowledgments}

Role of funding sources

Research reported in this publication was supported by grant number DA13580 from the National Institute on Drug Abuse (NIDA), grant number MH67281 from the National Institute of Mental Health (NIMH), and grant number AA020299 from the National Institute of Alcohol Abuse and Alcoholism (NIAAA), Whitbeck, PI. The content is solely the responsibility of the authors and does not necessarily represent the official views of NIDA, NIMH, or NIAAA.

\section{References}

Anthony JC, Warner LA, Kessler RC. Comparative epidemiology of dependence on tobacco, alcohol, controlled substances, and inhalants: Basic findings from the National Comorbidity Survey. Experimental and Clinical Psychopharmacology. 1994; 2(3):244-268.

Bachman JG, Wallace JM Jr, O’Malley PM, Johnston LD, Kurth CL, Neighbors HW. Racial/ethnic differences in smoking, drinking, and illicit drug use among American high school seniors, 197689. American Journal of Public Health. 1991; 81(3):372-377. [PubMed: 1994746]

Beals J, Novins D, Whitesell N, Spicer P, Mitchell C, Manson S. Prevalence of mental disorders and utilization of mental health services in two American Indian reservation populations: Mental health disparities in a national context. American Journal of Psychiatry. 2005; 162:1723-1732. [PubMed: 16135633]

Beauvais F. American Indians and alcohol. Alcohol Health \& Research World. 1998; 22:253-259. [PubMed: 15706751]

Blum RW, Harmon B, Harris L, Bergeisen L, Resnick MD. American Indian-Alaska native youth health. JAMA, the Journal of the American Medical Association. 1992; 267(12):1637-1644. [PubMed: 1542173]

Breslau N. Psychiatric comorbidity of smoking and nicotine dependence. Behavior Genetics. 1995; 25(2):95-101. [PubMed: 7733862]

Breslau N, Peterson EL, Schultz LR, Chilcoat HD, Andreski P. Major depression and stages of smoking: A longitudinal investigation. Archives of General Psychiatry. 1998; 55(2):161-166. [PubMed: 9477930]

Centers for Disease Control and Prevention. Cancer mortality among American Indians and Alaska Natives-United States, 1994-1998. Morbidity and Mortality Weekly Report (MMWR). 2003; 52(30):704-707. [PubMed: 12894057]

Cheadle JE, Sittner Hartshorn KJ. Marijuana use development over the course of adolescence among North American Indigenous youth. Social Science Research. 2012; 41:1227-1240. [PubMed: 23017929] 
Cheadle JE, Whitbeck LB. Alcohol use trajectories and problem drinking over the course of adolescence: A study of North American Indigenous youth and their caretakers. Journal of Health and Social Behavior. 2011; 52(2):228-245. [PubMed: 21558489]

Degenhardt L, Chiu W-T, Sampson N, Kessler R, Anthony J, Angermeyer M, et al. Toward a global view of alcohol, tobacco, cannabis, and cocaine use: Findings from the WHO World Mental Health Surveys. PLoS Medicine. 2008; 5(7):e141. http://dx.doi.org/10.1371/journal.pmed. 0050141. [PubMed: 18597549]

Ellgren M, Spano SM, Hurd YL. Adolescent cannabis exposure alters opiate intake and opioid limbic neuronal populations in adult rats. Neuropsychopharmacology. 2007; 32(3):607-615. [PubMed: 16823391]

Fergusson DM, Lynskey MT, Horwood LJ. Comorbidity between depressive disorders and nicotine dependence in a cohort of 16-year-olds. Archives of General Psychiatry. 1996; 53(11):1043-1047. [PubMed: 8911227]

Forster JL, Brokenleg I, Rhodes KL, Lamont GR, Poupart J. Cigarette smoking among American Indian youth in Minneapolis-St. Paul. American Journal of Preventive Medicine. 2008; 35(6):S449-S456. [PubMed: 19012838]

Hamburg BA, Kraemer HC, Jahnke W. A hierarchy of drug use in adolescence: Behavioral and attitudinal correlates of substantial drug use. The American Journal of Psychiatry. 1975; 132(11): 1155-1163. [PubMed: 1166892]

Higuera-Matas A, Soto-Montenegro ML, del Olmo N, Miguéns M, Torres I, Vaquero JJ, et al. Augmented acquisition of cocaine self-administration and altered brain glucose metabolism in adult female but not male rats exposed to a cannabinoid agonist during adolescence. Neuropsychopharmacology. 2008; 33(4):806-813. [PubMed: 17551541]

Juliano LM, Donny EC, Houtsmuller EJ, Stitzer ML. Experimental evidence for a causal relationship between smoking lapse and relapse. Journal of Abnormal Psychology. 2006; 115(1):166-173. [PubMed: 16492107]

Kandel D. Stages in adolescent involvement in drug use. Science. 1975; 190(4217):912-914. [PubMed: 1188374]

Kandel, DB., Yamaguchi, K. Developmental stages of involvement in substance use. In: Ott, P.Tartar, R., Ammerman, R., editors. Sourcebook on substance abuse: Etiology, epidemiology, assessment, and treatment. Needham Heights, MA: Allyn \& Bacon; 1999. p. 50-74.

Kandel, DB., Yamaguchi, K. Stages of drug involvement in the U.S. population. In: Kandel, D., editor. Stages and pathways to drug involvement. New York, NY: Cambridge University Press; 2002. p. 65-89.

Kandel DB, Yamaguchi K, Chen K. Stages of progression in drug involvement from adolescence to adulthood: Further evidence for the gateway theory. Journal of Studies on Alcohol and Drugs. 1992; 53(5):447-457.

Lawrence D, Mitrou F, Sawyer MG, Zubrick SR. Smoking status, mental disorders and emotional and behavioural problems in young people: Child and adolescent component of the National Survey of Mental Health and Wellbeing. Australian and New Zealand Journal of Psychiatry. 2010; 44(9): 805-814. [PubMed: 20815667]

Luengo MA, Kulis S, Marsiglia FF, Romero E, Gomez-Fraguela JA, Villar P, et al. A cross-national study of preadolescent substance use: Exploring differences between youth in Spain and Arizona. Substance Use \& Misuse. 2008; 43(11):1571-1593. [PubMed: 18752161]

Mackesy-Amiti ME, Fendrich M, Goldstein PJ. Sequence of drug use among serious drug users: Typical vs atypical progression. Drug and Alcohol Dependence. 1997; 45(3):185-196. [PubMed: 9179520]

May PA. The epidemiology of alcohol abuse among American Indians: The mythical and real properties. American Indian Culture and Research Journal. 1994; 18:121-143.

Miller KA, Beauvais F, Burnside M, Jumper-Thurman P. A comparison of American Indian and nonIndian fourth to sixth graders rates of drug use. Journal of Ethnicity in Substance Abuse. 2008; 7(3):258-267. [PubMed: 19042809] 
Novins DK, Barón AE. American Indian substance use: The hazards for substance use initiation and progression for adolescents aged 14 to 20 years. Journal of the American Academy of Child \& Adolescent Psychiatry. 2004; 43(3):316-324. [PubMed: 15076265]

Novins DK, Beals J, Mitchell CM. Sequences of substance use among American Indian adolescents. Journal of the American Academy of Child \& Adolescent Psychiatry. 2001; 40(10):1168-1174. [PubMed: 11589529]

Novins DK, Mitchell CM. Factors associated with marijuana use among American Indian adolescents. Addiction. 1998; 93(11):1693-1702. [PubMed: 9926532]

Pistis M, Perra S, Pillolla G, Melis M, Muntoni AL, Gessa GL. Adolescent exposure to cannabinoids induces long-lasting changes in the response to drugs of abuse of rat midbrain dopamine neurons. Biological Psychiatry. 2004; 56(2):86-94. [PubMed: 15231440]

Substance Abuse and Mental Health Services Administration. American Indian/Alaska native treatment admissions in rural and urban areas: 2000. 2003. Retrieved from http:// www.samhsa.gov/data/2k3/IndianMetroTx/IndianMetroTx.htm

Substance Abuse and Mental Health Services Administration. Results from the 2009 National Survey on Drug Use and Health. Volume I. summary of national findings. Rockville, MD: Office of Applied Studies; 2010. (NSDUH Series H-38A, HHS Publication No. SMA 10-4586)

Upadhyaya HP, Deas D, Brady KT, Kruesi M. Cigarette smoking and psychiatric comorbidity in children and adolescents. Journal of the American Academy of Child \& Adolescent Psychiatry. 2002; 41(11):1294-1305. [PubMed: 12410071]

Vaughn M, Wallace J, Perron B, Copeland V, Howard M. Does marijuana use serve as a gateway to cigarette use for high-risk African-American youth? The American Journal of Drug and Alcohol Abuse. 2008; 34(6):782-791. [PubMed: 19016184]

Wells JE, McGee MA. Violations of the usual sequence of drug initiation: Prevalence and associations with the development of dependence in the New Zealand Mental Health Survey. Journal of Studies on Alcohol and Drugs. 2008; 69(6):789-795. [PubMed: 18925336]

Whitbeck L, Hoyt D, Johnson K, Chen X. Mental disorders among parents/caretakers of American Indian early adolescents in the northern Midwest. Social Psychiatry and Psychiatric Epidemiology. 2006; 41:632-640. [PubMed: 16779502]

Whitbeck LB, Sittner Hartshorn KJ, McQuillan J, Crawford DM. Factors associated with growth in daily smoking among Indigenous adolescents. Journal of Research on Adolescence. 2012; 22(4): 768-781. [PubMed: 23794792]

Whitbeck LB, Yu M, McChargue DE, Crawford DM. Depressive symptoms, gender, and growth in cigarette smoking among indigenous adolescents. Addictive Behaviors. 2009; 34(5):421-426. [PubMed: 19167169]

Whitesell NR, Beals J, Mitchell CM, Novins DK, Spicer P, O’Connell J, et al. Marijuana initiation in 2 American Indian reservation communities: Comparisons with a national sample. American Journal of Public Health. 2007; 97(7):1311-1318. [PubMed: 17538072]

Whitesell NR, Kaufman CE, Keane EM, Big Crow CB, Shangreau C, Mitchell CM. Patterns of substance use initiation among young adolescents in a Northern plains American Indian tribe. The American Journal of Drug and Alcohol Abuse. 2012; 38(5):383-388. [PubMed: 22931070]

Willi C, Bodenmann P, Ghali WA, Faris PD, Cornuz J. Active smoking and the risk of type 2 diabetes. JAMA, the Journal of the American Medical Association. 2007; 298(22):2654-2664. [PubMed: 18073361]

Wu Z, Temple JR, Shokar NK, Nguyen-Oghalai TU, Grady JJ. Differential racial/ethnic patterns in substance use initiation among young, low-income women. The American Journal of Drug and Alcohol Abuse. 2010; 36(2):123-129. [PubMed: 20337510] 


\title{
Appendix A. Substance use initiation orderings - three substance categorization scheme
}

\author{
a) Consistent \\ Substance A only \\ Substance A $\rightarrow$ substance B \\ Substance A $\rightarrow$ substance $\mathrm{B} \rightarrow$ substance $\mathrm{C}$ \\ b) Inconsistent \\ Substance B only \\ Substance C only \\ Substances $B$ and $C$ at the same age \\ Substance B $\rightarrow$ substance A \\ Substance $\mathrm{C} \rightarrow$ substance $\mathrm{A}$ \\ Substance B $\rightarrow$ substance C \\ Substances B and C at the same age $\rightarrow$ substance A \\ Substance $\mathrm{C} \rightarrow$ substances $\mathrm{A}$ and $\mathrm{B}$ at the same age \\ Substance $\mathrm{C} \rightarrow$ substance $\mathrm{B} \rightarrow$ substance $\mathrm{C}$ \\ Substance $\mathrm{A} \rightarrow$ substance $\mathrm{C}$ \\ Substance B $\rightarrow$ substance C \\ Substances A and C at the same age $\rightarrow$ substance $B$ \\ Substance $\mathrm{B} \rightarrow$ substances $\mathrm{A}$ and $\mathrm{C}$ at the same age \\ Substance A $\rightarrow$ substance $\mathrm{C} \rightarrow$ substance $\mathrm{B}$ \\ Substance $\mathrm{B} \rightarrow$ substance $\mathrm{A} \rightarrow$ substance $\mathrm{C}$ \\ Substance $\mathrm{B} \rightarrow$ substance $\mathrm{C} \rightarrow$ substance A \\ Substance $\mathrm{C} \rightarrow$ substance $\mathrm{A} \rightarrow$ substance $\mathrm{B}$ \\ c) Non-informative \\ No substance use \\ Substances A and B at the same age \\ Substances $\mathrm{A}$ and $\mathrm{C}$ at the same age \\ Substances A, B, and C at the same age \\ Substances A and B at the same age $\rightarrow$ substance C \\ Substance $A \rightarrow$ substances $B$ and $C$ at the same age
}




\section{HIGHLIGHTS}

- When considering the sequencing of two substances, nicotine initiation was more likely to precede both alcohol and marijuana initiation.

- When considering the sequencing of two substances, alcohol initiation was far more likely to precede marijuana initiation than marijuana initiation was to precede alcohol initiation.

- More nuanced consideration of the sequencing of substance use initiation showed that, by far, the most common sequencing was nicotine and/or alcohol initiation prior to marijuana initiation. 


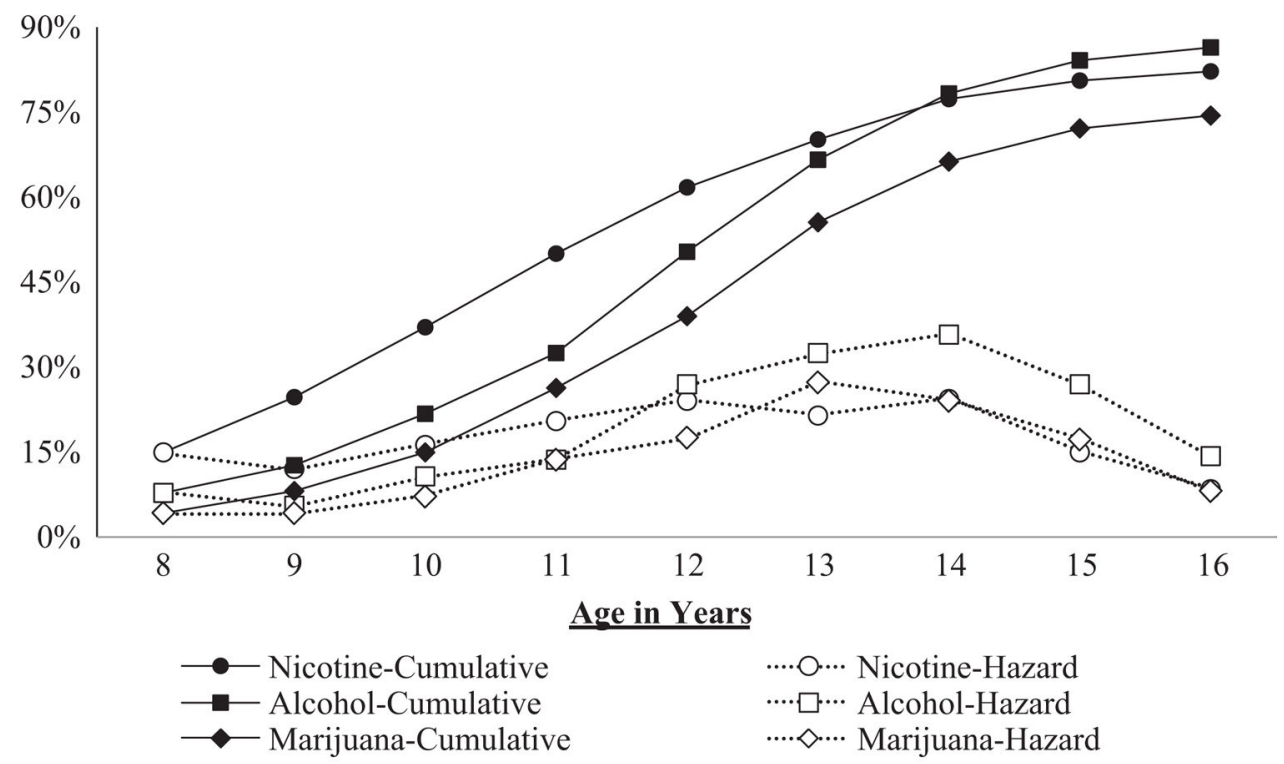

Fig. 1.

Cumulative initiation and initiation hazard rates by age. 


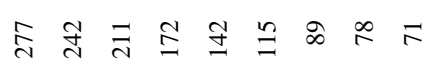

ह

ल సి శ్ల

in

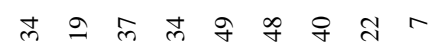

$a \infty \vec{\sim}$

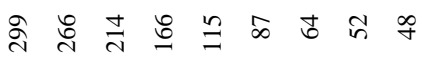

तิ

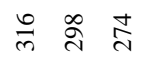

ஏ

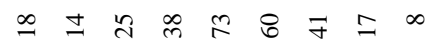

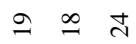

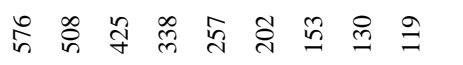

శู่

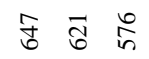

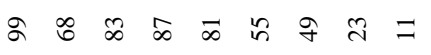

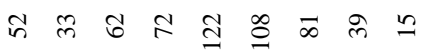

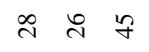

焉 

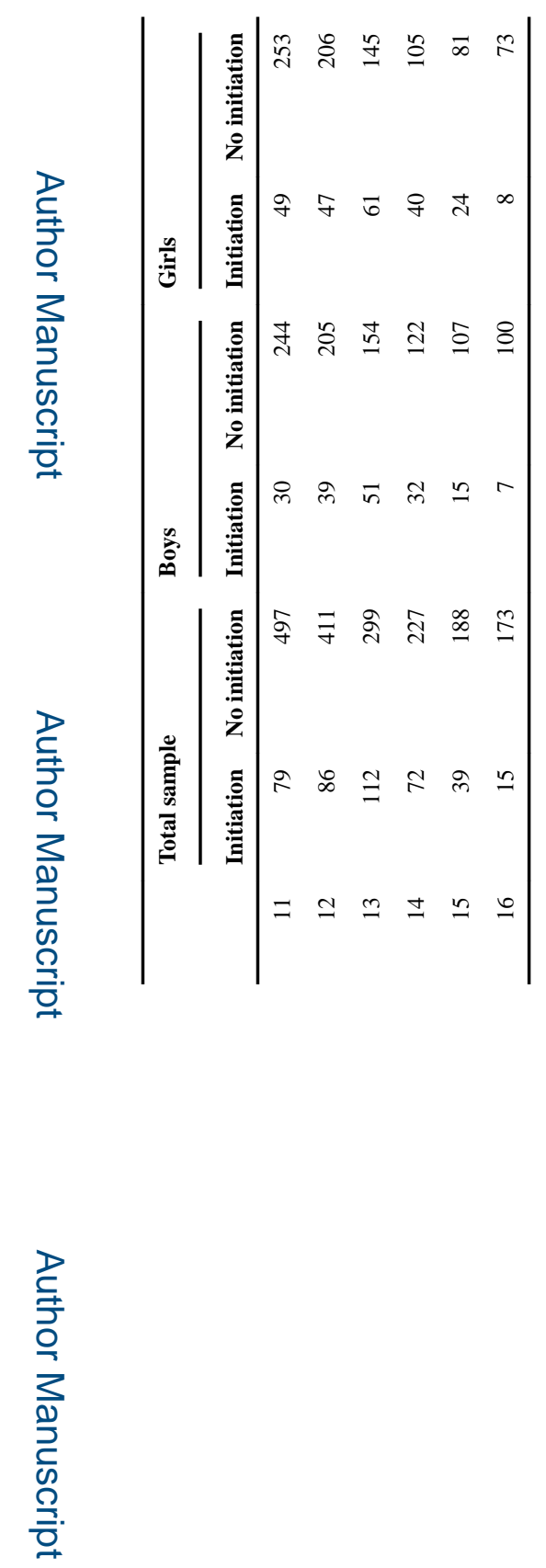

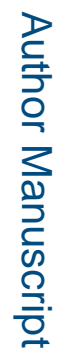

Addict Behav. Author manuscript; available in PMC 2018 June 22. 


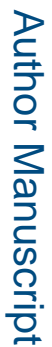

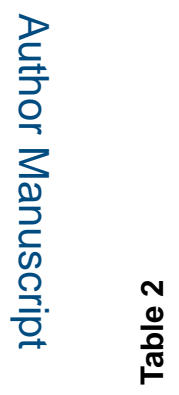

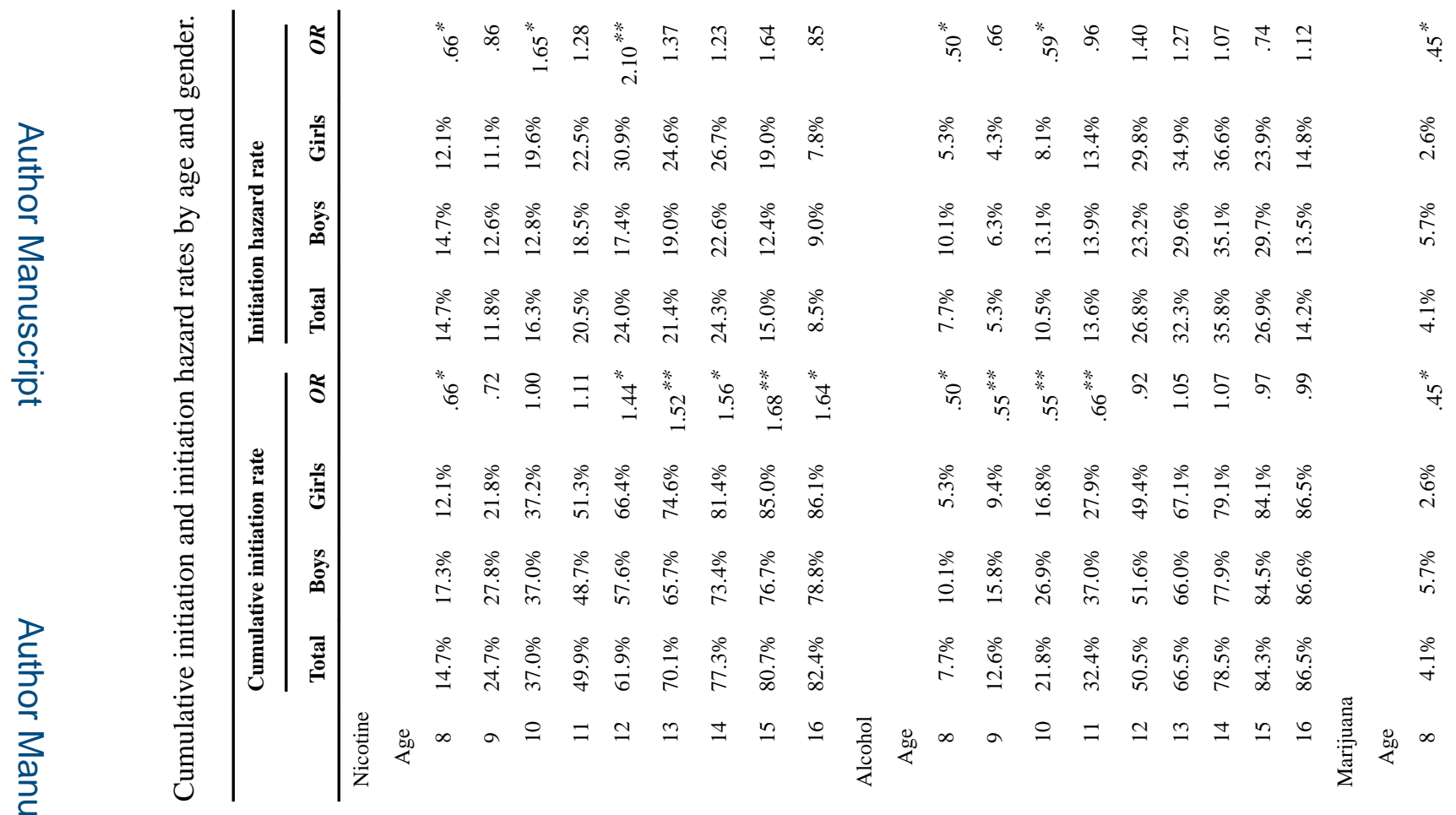




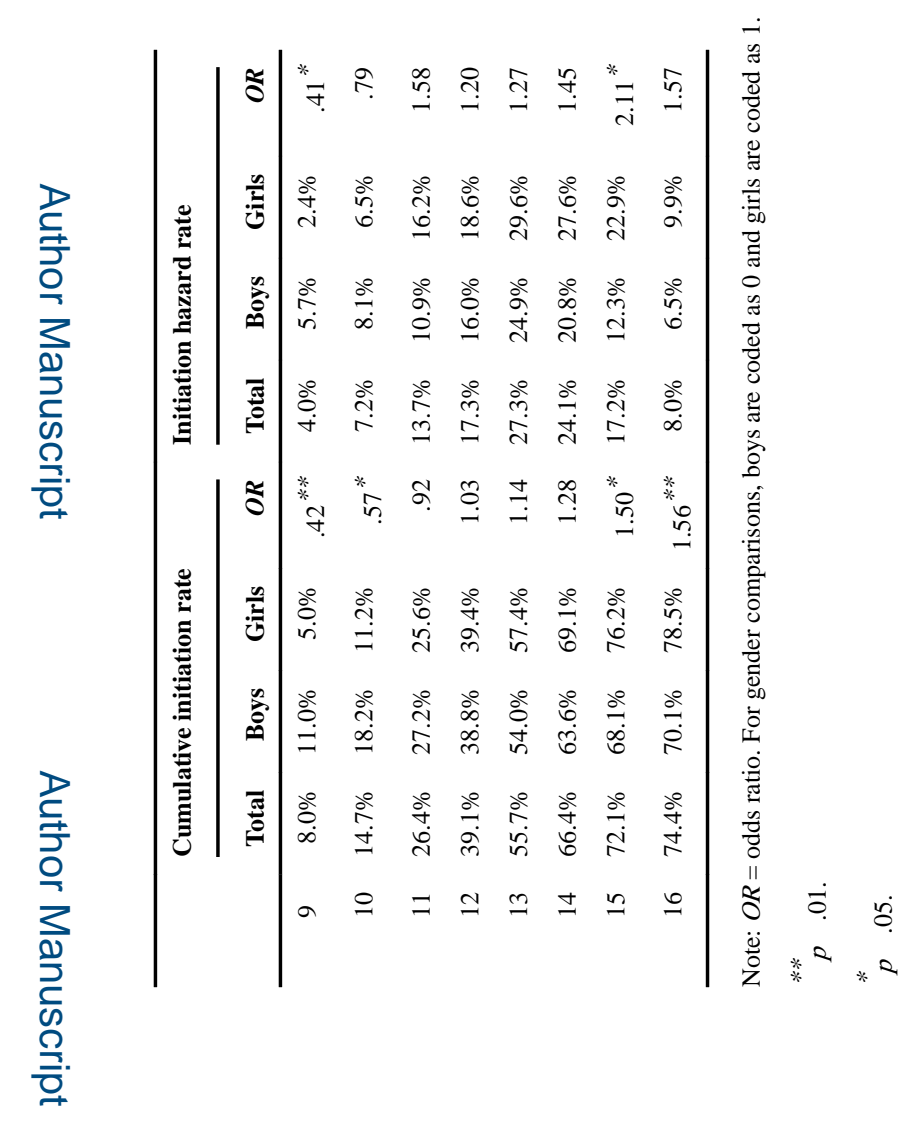

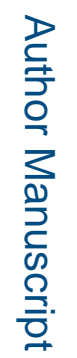

로을

Addict Behav. Author manuscript; available in PMC 2018 June 22. 


\section{Table 3}

\section{Results for two substance orderings.}

\begin{tabular}{|c|c|c|c|}
\hline & Consistent (comparison category) & Inconsistent & Non-informative \\
\hline \multicolumn{4}{|l|}{ Full sample } \\
\hline Nicotine $\rightarrow$ alcohol & $48.6 \%{ }^{\mathrm{c}}$ & $26.2 \%$ ** & $25.2 \% * *$ \\
\hline Nicotine $\rightarrow$ marijuana & $56.9 \%^{\mathrm{d}}$ & $13.5 \%{ }^{* *}$ & $29.6 \% * *$ \\
\hline Alcohol $\rightarrow$ nicotine & $26.2 \% \mathrm{~b}$ & $48.6 \%{ }^{* *}$ & $25.2 \%$ \\
\hline Alcohol $\rightarrow$ marijuana & $43.7 \%^{\mathrm{c}}$ & $27.0 \% * *$ & $29.3 \% * *$ \\
\hline Marijuana $\rightarrow$ nicotine & $13.5 \% \mathrm{a}$ & $26.9 \%{ }^{* *}$ & $29.6 \%{ }^{* *}$ \\
\hline Marijuana $\rightarrow$ alcohol & $27.0 \%^{\mathrm{b}}$ & $43.7 \%^{* *}$ & $29.3 \%$ \\
\hline \multicolumn{4}{|l|}{ Boys } \\
\hline Nicotine $\rightarrow$ alcohol & $43.7 \%^{c}$ & $31.7 \%$ ** & $24.6 \%{ }^{* *}$ \\
\hline Nicotine $\rightarrow$ marijuana & $51.8 \%$ d & $15.3 \%{ }^{* *}$ & $32.9 \%{ }^{* *}$ \\
\hline Alcohol $\rightarrow$ nicotine & $31.7 \%^{\mathrm{b}}$ & $43.7 \%$ ** & $24.6 \%$ ** \\
\hline Alcohol $\rightarrow$ marijuana & $45.2 \%^{\mathrm{c}}$ & $27.5 \%{ }^{* *}$ & $27.2 \%{ }^{* *}$ \\
\hline Marijuana $\rightarrow$ nicotine & $15.3 \%^{\mathrm{a}}$ & $51.8 \%{ }^{* *}$ & $32.9 \% * *$ \\
\hline Marijuana $\rightarrow$ alcohol & $27.5 \%$ b & $45.2 \%{ }^{* *}$ & $27.2 \%$ \\
\hline \multicolumn{4}{|l|}{ Girls } \\
\hline Nicotine $\rightarrow$ alcohol & $53.4 \% \mathrm{e}$ & $20.8 \% * *$ & $25.8 \%{ }^{* *}$ \\
\hline Nicotine $\rightarrow$ marijuana & $61.9 \%^{\mathrm{f}}$ & $11.7 \%^{* *}$ & $26.4 \% * *$ \\
\hline Alcohol $\rightarrow$ nicotine & $20.8 \%^{\mathrm{b}}$ & $53.4 \%{ }^{* *}$ & $25.8 \%{ }^{* *}$ \\
\hline Alcohol $\rightarrow$ marijuana & $42.2 \%^{\mathrm{d}}$ & $26.4 \% * *$ & $31.4 \%{ }^{* *}$ \\
\hline Marijuana $\rightarrow$ nicotine & $11.7 \%{ }^{\mathrm{a}}$ & $61.9 \%{ }^{* *}$ & $26.4 \% * *$ \\
\hline Marijuana $\rightarrow$ alcohol & $26.4 \%^{\mathrm{c}}$ & $42.2 \% * *$ & $31.4 \% *$ \\
\hline
\end{tabular}

Note: Asterisks indicate comparisons across rows with the consistent category as the comparison category. Superscript letters are comparisons between percentages in the consistent column, separately for the total sample, boys only, and girls only. Similar superscripts indicate statistical equivalence whereas different superscripts indicate statistically significant differences.

***

$p<.01$.

$p<.05$. 


\section{Table 4}

Results for paired two substance orderings.

\begin{tabular}{|c|c|c|c|}
\hline & Consistent (comparison category) & Inconsistent & Non-informative \\
\hline \multicolumn{4}{|l|}{ Full sample } \\
\hline Nicotine and/or alcohol $\rightarrow$ marijuana & $68.4 \% \mathrm{f}$ & $8.6 \%$ ** & $23.0 \% * *$ \\
\hline Nicotine and/or marijuana $\rightarrow$ alcohol & $54.2 \% \mathrm{e}^{\mathrm{e}}$ & $21.3 \%{ }^{* *}$ & $24.4 \%^{* *}$ \\
\hline Alcohol and/or marijuana $\rightarrow$ nicotine & $32.4 \% \mathrm{c}$ & $38.8 \%{ }^{* *}$ & $28.7 \%$ * \\
\hline Nicotine $\rightarrow$ alcohol and/or marijuana & $38.8 \%{ }^{\mathrm{d}}$ & $32.4 \%$ ** & $28.7 \%{ }^{* *}$ \\
\hline Alcohol $\rightarrow$ nicotine and/or marijuana & $21.3 \%^{\mathrm{b}}$ & $54.2 \% * *$ & $24.4 \%^{*}$ \\
\hline Marijuana $\rightarrow$ nicotine and/or alcohol & $8.6 \%{ }^{\mathrm{a}}$ & $68.4 \%{ }^{* *}$ & $23.0 \%{ }^{* *}$ \\
\hline \multicolumn{4}{|l|}{ Boys } \\
\hline Nicotine and/or alcohol $\rightarrow$ marijuana & $67.4 \%{ }^{\mathrm{f}}$ & $10.2 \%$ ** & $22.5 \%{ }^{* *}$ \\
\hline Nicotine and/or marijuana $\rightarrow$ alcohol & $50.3 \% \mathrm{e}^{\mathrm{e}}$ & $26.3 \%{ }^{* *}$ & $23.4 \%{ }^{* *}$ \\
\hline Alcohol and/or marijuana $\rightarrow$ nicotine & $39.2 \%{ }^{\mathrm{d}}$ & $33.5 \%$ * & $27.2 \%{ }^{* *}$ \\
\hline Nicotine $\rightarrow$ alcohol and/or marijuana & $33.5 \%^{\mathrm{c}}$ & $39.2 \% *$ & $27.2 \%{ }^{*}$ \\
\hline Alcohol $\rightarrow$ nicotine and/or marijuana & $26.3 \%^{\mathrm{b}}$ & $50.3 \%{ }^{* *}$ & $23.4 \%$ \\
\hline Marijuana $\rightarrow$ nicotine and/or alcohol & $10.2 \% \mathrm{a}^{\mathrm{a}}$ & $67.4 \%^{* *}$ & $22.5 \%{ }^{* *}$ \\
\hline \multicolumn{4}{|l|}{ Girls } \\
\hline Nicotine and/or alcohol $\rightarrow$ marijuana & $69.5 \% \mathrm{f}$ & $7.0 \%$ ** & $23.5 \% * *$ \\
\hline Nicotine and/or marijuana $\rightarrow$ alcohol & $58.1 \% \mathrm{e}^{\mathrm{e}}$ & $16.4 \%{ }^{* *}$ & $25.5 \%{ }^{* *}$ \\
\hline Alcohol and/or marijuana $\rightarrow$ nicotine & $25.8 \%^{\mathrm{c}}$ & $44.0 \%{ }^{* *}$ & $30.2 \%$ \\
\hline Nicotine $\rightarrow$ alcohol and/or marijuana & $44.0 \%{ }^{\mathrm{d}}$ & $25.8 \%{ }^{* *}$ & $30.2 \%^{* *}$ \\
\hline Alcohol $\rightarrow$ nicotine and/or marijuana & $16.4 \% \mathrm{~b}$ & $58.1 \%{ }^{* *}$ & $25.5 \% * *$ \\
\hline Marijuana $\rightarrow$ nicotine and/or alcohol & $7.0 \% \mathrm{a}$ & $69.5 \%$ ** & $23.5 \%{ }^{* *}$ \\
\hline
\end{tabular}

Note: Asterisks indicate comparisons across rows with the consistent category as the comparison category. Superscript letters are comparisons between percentages in the consistent column, separately for the total sample, boys only, and girls only. Similar superscripts indicate statistical equivalence whereas different superscripts indicate statistically significant differences.

** $p<.01$

* $p<.05$. 


\section{Table 5}

Results for three substance orderings.

\begin{tabular}{|c|c|c|c|}
\hline & Consistent (comparison category) & Inconsistent & Non-informative \\
\hline \multicolumn{4}{|l|}{ Full sample } \\
\hline Nicotine $\rightarrow$ alcohol $\rightarrow$ marijuana & $15.9 \%^{\mathrm{c}}$ & $50.8 \% * *$ & $33.3 \%{ }^{* *}$ \\
\hline Nicotine $\rightarrow$ marijuana $\rightarrow$ alcohol & $13.3 \%^{\mathrm{c}}$ & $54.1 \%{ }^{* *}$ & $32.6 \%{ }^{* *}$ \\
\hline Alcohol $\rightarrow$ nicotine $\rightarrow$ marijuana & $15.3 \% \mathrm{c}$ & $58.5 \%{ }^{* *}$ & $26.2 \% * *$ \\
\hline Alcohol $\rightarrow$ marijuana $\rightarrow$ nicotine & $7.9 \%^{\mathrm{b}}$ & $71.6 \% \%^{* *}$ & $20.6 \% * *$ \\
\hline Marijuana $\rightarrow$ nicotine $\rightarrow$ alcohol & $3.1 \%{ }^{\mathrm{a}}$ & $72.7 \%^{* *}$ & $24.1 \%{ }^{* * *}$ \\
\hline Marijuana $\rightarrow$ alcohol $\rightarrow$ nicotine & $2.5 \% \mathrm{a}$ & $78.2 \%{ }^{* *}$ & $19.3 \%{ }^{* *}$ \\
\hline \multicolumn{4}{|l|}{ Boys } \\
\hline Nicotine $\rightarrow$ alcohol $\rightarrow$ marijuana & $13.2 \% \mathrm{~b}$ & $56.6 \%{ }^{* *}$ & $30.2 \%{ }^{* *}$ \\
\hline Nicotine $\rightarrow$ marijuana $\rightarrow$ alcohol & $12.6 \% \%^{\mathrm{b}}$ & $56.9 \%^{* *}$ & $30.5 \%{ }^{* *}$ \\
\hline Alcohol $\rightarrow$ nicotine $\rightarrow$ marijuana & $18.9 \%^{\mathrm{c}}$ & $54.8 \% * *$ & $26.3 \%{ }^{* *}$ \\
\hline Alcohol $\rightarrow$ marijuana $\rightarrow$ nicotine & $10.5 \%^{\mathrm{b}}$ & $67.4 \%{ }^{* *}$ & $22.2 \% * *$ \\
\hline Marijuana $\rightarrow$ nicotine $\rightarrow$ alcohol & $3.6 \%{ }^{\mathrm{a}}$ & $72.2 \%^{* * *}$ & $24.3 \%{ }^{* *}$ \\
\hline Marijuana $\rightarrow$ alcohol $\rightarrow$ nicotine & $2.7 \% \mathrm{a}^{\mathrm{a}}$ & $77.5 \%$ ** & $19.8 \% * *$ \\
\hline \multicolumn{4}{|l|}{ Girls } \\
\hline Nicotine $\rightarrow$ alcohol $\rightarrow$ marijuana & $18.5 \%{ }^{\mathrm{d}}$ & $45.2 \%{ }^{* *}$ & $36.4 \%^{* * *}$ \\
\hline Nicotine $\rightarrow$ marijuana $\rightarrow$ alcohol & $14.1 \%^{\mathrm{c}}$ & $51.3 \%{ }^{* *}$ & $34.6 \% * *$ \\
\hline Alcohol $\rightarrow$ nicotine $\rightarrow$ marijuana & $11.7 \%^{\mathrm{c}}$ & $62.2 \%{ }^{* *}$ & $26.1 \%{ }^{* *}$ \\
\hline Alcohol $\rightarrow$ marijuana $\rightarrow$ nicotine & $5.3 \%^{\mathrm{b}}$ & $75.7 \%$ *** & $19.1 \%{ }^{* *}$ \\
\hline Marijuana $\rightarrow$ nicotine $\rightarrow$ alcohol & $2.6 \% \mathrm{a}^{\mathrm{a}}$ & $73.3 \%^{* *}$ & $24.0 \% * *$ \\
\hline Marijuana $\rightarrow$ alcohol $\rightarrow$ nicotine & $2.3 \% \mathrm{a}^{\mathrm{a}}$ & $78.9 \%^{* *}$ & $18.8 \%{ }^{* *}$ \\
\hline
\end{tabular}

Note: Asterisks indicate comparisons across rows with the consistent category as the comparison category. Superscript letters are comparisons between percentages in the consistent column, separately for the total sample, boys only, and girls only. Similar superscripts indicate statistical equivalence whereas different superscripts indicate statistically significant differences.

***.01. 